\title{
AVALIAÇÃO DA HIDRODINÂMICA DE UM LAVADOR VENTURI: DADOS EXPERIMENTAIS E SIMULAÇÃO NUMÉRICA
}

\author{
V. K. HONDA ${ }^{1}$, R. BÉTTEGA ${ }^{1}$, V. G. GUERRA ${ }^{1 *}$ \\ ${ }^{1}$ Universidade Federal de São Carlos, Departamento de Engenharia Química \\ e-mail: vadila@ufscar.br
}

\begin{abstract}
RESUMO
O lavador Venturi é um equipamento de reconhecida eficiência na remoção de micropartículas de efluentes gasosos. O seu princípio de funcionamento envolve a injeção de um líquido de lavagem que é responsável pela captura das partículas. $\mathrm{O}$ líquido, geralmente introduzido através de pequenos orifícios, quando entra em contato com o ar em altas velocidades gera inúmeras gotas. A distribuição uniforme das gotas no lavador promove o contato adequado entre líquido e partícula, influenciando a eficiência de coleta. Desta forma, estudos acerca de condições operacionais considerando o uso apropriado de líquido e a sua distribuição no lavador, bem como modelos computacionais para sua previsão, são relevantes. Neste contexto, o presente estudo tem por objetivo avaliar experimentalmente e numericamente a distribuição de líquido em um lavador Venturi operando em diferentes condições. O comportamento fluidodinâmico do escoamento ar-água foi simulado utilizando o pacote comercial ANSYS FLUENT 14.0 através da implementação de um modelo de trajetória para fase discreta. Os resultados simulados acerca da hidrodinâmica do equipamento apresentaram desvios baixos quando comparados com os experimentais, já que tanto o perfil de pressão, a dispersão de líquido, quanto à porcentagem de filme aderido as paredes apresentaram comportamento em concordância com os previstos nas simulações.
\end{abstract}

\section{INTRODUÇÃO}

Os lavadores Venturi são equipamentos altamente eficientes na coleta de materiais particulados, inclusive na faixa de pó respirável, a mais danosa a saúde. O equipamento é constituído basicamente por uma seção convergente, um duto contendo uma constrição, denominada garganta, e por fim, uma seção divergente. O princípio de funcionamento dos lavadores Venturi envolve a introdução de líquido, geralmente feita através de orifícios localizados na garganta do lavador. Nessa forma de injeção, o líquido adentra o equipamento na forma de um jato que, em contato com o gás em alta velocidade, se atomiza formando inúmeras gotas, as quais são responsáveis pela coleta das partículas. A energia necessária para atomizar o líquido e acelerá-lo é proveniente do gás em alta velocidade, devido à troca de quantidade de movimento do gás com o líquido injetado. A perda de energia da corrente gasosa reflete-se na perda de carga do sistema, que pode ser estimada com base na queda de pressão do equipamento. Do ponto de visto econômico, a queda de pressão é o critério mais importante a ser levado em consideração. Já o desempenho de coleta é, em grande parte, influenciado pela uniformidade da distribuição de gotas no interior do lavador. É importante salientar que uma parte do líquido introduzido no lavador deposita-se nas paredes do equipamento e 


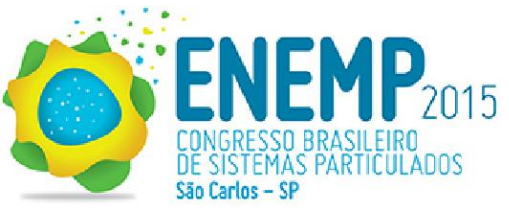

escoa como um filme. O filme depositado nas paredes não contribui com a coleta de partículas pois apresenta área superficial muito inferior as das gotas, sendo também importante estudos fluidodinâmicos a fim de minimizá-lo.

A importância da distribuição de gotas no desempenho de lavadores do Venturi foi evidenciada já nos primeiros estudos desse dispositivo (Ekman e Johnstone, 1951). A uniformidade da distribuição de líquido em lavadores Venturi está relacionada a condições operacionais, como a vazão de injeção de líquido, e as condições de projeto, como o número e posicionamento dos orifícios de injeção de líquido na garganta do equipamento. $\mathrm{Na}$ prática industrial os lavadores Venturi possuem diversos orifícios de injeção de líquido. A distribuição adequada destes orifícios na garganta do lavador pode melhorar a distribuição do líquido em seu interior e favorecer o contato gota-partícula, melhorando a eficiência de coleta. Em estudo desenvolvido por Guerra (2009) e Guerra et al. (2009) em um lavador Venturi retangular, os autores observaram através de imagens da garganta do lavador uma significativa variação da distribuição do líquido em função da vazão de ar. Os autores também evidenciaram a alteração do diâmetro da gota coletada em função do número de orifícios de injeção. Desta forma, o número de orifícios de injeção de líquido mostrou-se significativamente relevante na qualidade da distribuição do líquido na garganta do lavador Venturi estudado.

Dentre as condições operacionais, a vazão de injeção de líquido é uma das condições que proporcionam variações significativas, tanto na queda pressão, quanto na dispersão das gotas em lavadores Venturi. A distribuição de líquido pode ajudar o projetista a determinar as condições de melhor cobertura de garganta, na qual tem-se maior concentração de líquido na região central do equipamento e mínima deposição de líquido em suas paredes, isto é, escoando como filme.

Nesse contexto, estudos mais aprofundados visando determinar as melhores condições operacionais utilizando lavadores Venturi se mostram relevantes. Dentro do panorama de desenvolvimento de projetos e determinação das melhores condições operacionais, a Simulação Numérica em Mecânica de Fluidos (CFD - Computational Fluid Dynamics) apresenta grande contribuição, pois permite prever o comportamento fluidodinâmico de equipamentos industriais, como os lavadores.

\section{MATERIAIS E MÉTODOS}

O equipamento utilizado nos testes experimentais foi um lavador Venturi constituído por módulos de acrílico que possui uma seção transversal retangular e uma garganta de dimensões de $27 \times 40 \mathrm{~mm}$. A injeção de líquido foi realizada por uma bomba helicoidal que transportava água de um reservatório até o primeiro módulo da garganta do lavador, no qual havia quatro orifícios de injeção de $1 \mathrm{~mm}$ de diâmetro, um em cada parede da garganta. Um esquema do equipamento utilizado com as suas principais dimensões pode ser visto na Figura 1.

Figura 1 - Lavador Venturi em módulos utilizado nos testes experimentais. (a) vista frontal (b) vista lateral.

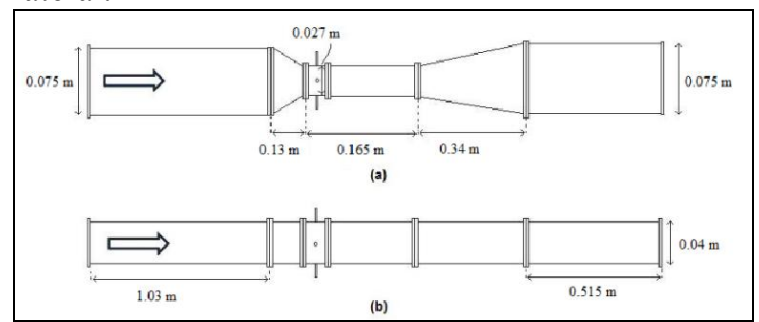

Fonte: Autor (2015).

Foram realizadas medidas de pressão em diferentes pontos distribuídos ao longo do equipamento. 


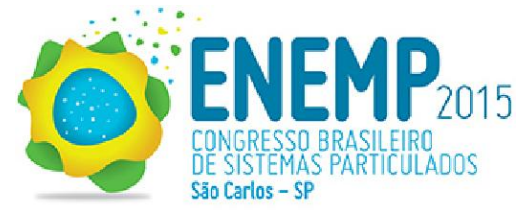

A dispersão de gotas foi medida pelo método de amostragem isocinética, método utilizado com sucesso por Viswanathan et al. (1984) e por Gonçalves et al. (2004). Para se empregar esse método utilizou-se uma seção de teste em acrílico, acoplada entre a garganta e o difusor. Essa seção de teste possuía uma sonda na qual ar e parte das gotas que escoam pela garganta são sugadas para um pequeno ciclone de alumínio contendo uma coluna de sílica gel em seu topo. A função do ciclone é separar a corrente bifásica e reter o líquido. A sucção foi realizada por uma bomba e ajustada por um medidor de vazão para que a velocidade de sucção fosse igual à velocidade do ar no interior da garganta. A Figura 2 apresenta a vista geral do aparato utilizado para amostragem das gotas.

Figura 2 - Vista geral do equipamento para medida da dispersão de gotas.

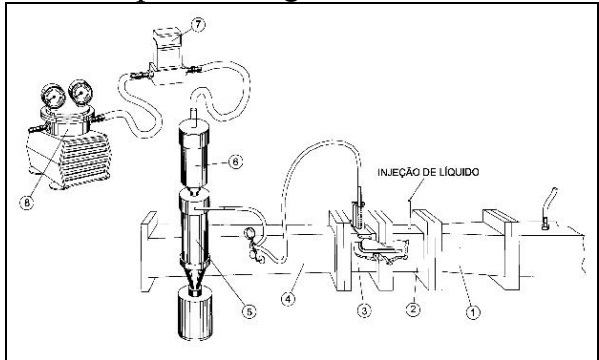

Fonte: Autor (2015).

Nos testes realizados optou-se por medir apenas os pontos centrais do plano de amostragem, como pode ser visto na Figura 3. A dispersão de gotas no interior da garganta foi avaliada a uma distância de $1,6 \mathrm{~cm}$ dos orifícios de injeção de líquido. Os testes experimentais realizados estão apresentados na Tabela 1.

Tabela 1 - Condições experimentais avaliadas

\begin{tabular}{|c|c|c|c|}
\hline Experimento & $\begin{array}{c}\text { Número de } \\
\text { orifícios }\end{array}$ & $\begin{array}{c}\mathrm{Ql} \\
(\mathrm{ml} / \mathrm{min})\end{array}$ & $\begin{array}{c}\mathrm{Vg} \\
(\mathrm{m} / \mathrm{s})\end{array}$ \\
\hline E-1 & 1 & 300 & 64 \\
\hline E-2 & 2 & 300 & 59 \\
\hline E-3 & 2 & 600 & 59 \\
\hline E-4 & 2 & 900 & 59 \\
\hline E-5 & 2 & 600 & 74 \\
\hline
\end{tabular}

A dispersão foi medida através do fluxo mássico de líquido recolhido em cada ponto do plano transversal mostrado na Figura 3.

A fração de líquido que ficou aderida como um filme as paredes do equipamento foi medida acoplando-se uma peça adicional ao final da garganta. A peça para extração do filme possuía fendas em suas paredes as quais permitiam que o filme escoasse para fora do equipamento. A Figura 4 apresenta um desenho esquemático da peça para extração do filme. Conforme ilustrado na figura, o filme líquido era desviado pela lâmina em direção à fenda, acumulava-se em um pequeno reservatório, e escorria para fora do lavador Venturi, passando por um canal até um recipiente de coleta. A fração de filme foi calculada, coletando o líquido aderido as paredes por um tempo determinado e dividindo o valor pela vazão de líquido injetada no equipamento.

Figura 3 - Vista geral do equipamento para medida da dispersão de gotas.

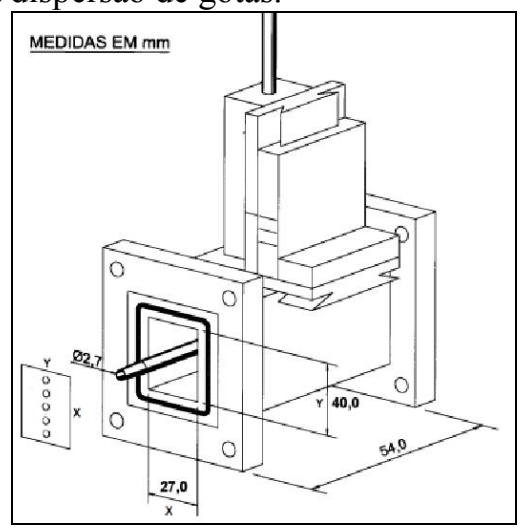

Fonte: Autor (2015).

Figura 4 - Esquema da peça utilizada para extração do filme líquido.

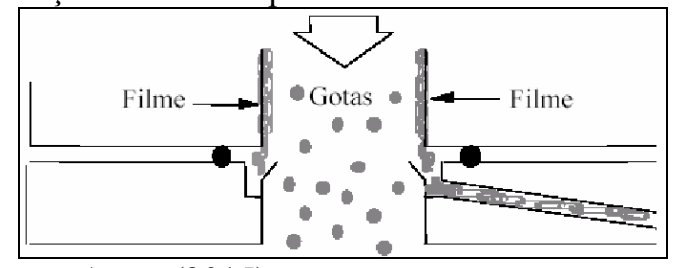

Fonte: Autor (2015). 


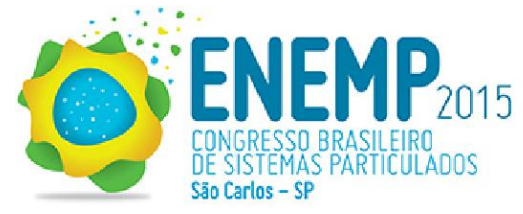

A solução matemática do problema foi realizada utilizando-se o pacote comercial de CFD ANSYS FLUENT 14.0. Foram utilizados o modelo lagrangeano de fase discreta para prever a dispersão do líquido no equipamento. Muitos dos parâmetros do modelo foram estabelecidos com base no artigo de Ananthanrayanan e Viswanathan (1999), com exceção dos parâmetros de distribuição de tamanho de gotas.

A distribuição de tamanho de gotas foi obtida experimentalmente utilizando-se o equipamento Malvern Spraytec. O princípio de funcionamento desse equipamento é a difração de raios laser. O laser, quando incide sobre uma gota, faz com que parte da energia luminosa seja refletida, parte difratada e outra absorvida. O ângulo de difração é inversamente proporcional ao tamanho da gota, tornando-se assim possível obter a distribuição do tamanho de gotas em um spray. O modelo de distribuição de tamanho de gotas ajustado aos dados experimentais foi o de Rosin-Rammler, por ser o mais adequado para distribuição gotas no interior de lavadores Venturi (Guerra et al., 2009; Guerra, 2009). Os valores dos parâmetros do modelo de Rosin-Rammler (espalhamento $(n)$ e diâmetro médio $(\bar{D})$ ) foram obtidos através de ajuste para posterior utilização nas simulações.

$\mathrm{O}$ acoplamento pressão-velocidade foi solucionado através do método SIMPLE, utilizando-se discretizações Upwind de segunda-ordem para as equações do movimento e de turbulência (Fluent, 2011). O modelo de turbulência adotada nas simulações foi o modelo k- $\varepsilon$ RNG. Efeitos gravitacionais foram desprezados nas simulações. Os critérios de convergência para todas variáveis do problema foram mantidos em $10^{-4}$, com parâmetros de relaxação na faixa de 0,2 a 0,4. A malha computacional foi elaborada com o software GAMBIT 2.4.6, a partir de um teste de independência de malha, respeitando-se as dimensões e demais características geométricas do equipamento. A malha híbrida adotada neste trabalho foi composta por 1.178.610 células, contando com 2.540.298 faces e 333.383 nós. Células hexaédricas foram utilizadas nas regiões de entrada e saída da garganta do equipamento e células tetraédricas na região da garganta, que por sua vez continham os orifícios de injeção de líquido.

Para avaliar numericamente a fração de líquido que escoava como um filme aderido às paredes do equipamento, a quantidade de líquido nas paredes foi calculada por meio de uma média mássica da concentração de líquido sobre as paredes da garganta normalizadas pela concentração média axial obtida ao final da garganta do lavador.

\section{RESULTADOS E DISCUSSÃO}

A Figura 5 mostra o perfil de pressão experimental e simulado para a condição E-3. As demais condições experimentais avaliadas apresentaram comportamento equivalente e mostraram que independentemente da configuração de injeção, velocidade do gás e vazão de líquido, o comportamento da pressão ao longo do equipamento, obtidas experimentalmente e simulados, apresentaram desvios baixos.

A Figura 6 apresenta a distribuição de tamanho de gotas medida experimentalmente e a ajustada com o modelo de distribuição de Rosin-Rammler para a condição E-1. Como pode ser observado na Figura 6, o modelo de distribuição de Rosin-Rammler se ajustou adequadamente aos dados experimentais. Através do ajuste foi possível determinar os dois parâmetros do modelo de distribuição de Rosin-Rammler ( $\bar{D}$ e n) para cada condição experimental, como mostrado na Tabela 2 . Segundo estudos realizados por Honda et al.(2014) e Guerra et al. (2011) o diâmetro médio da gota afeta a dispersão de líquido no equipamento e a porcentagem de filme depositado nas paredes. 
Figura 5 - Medida experimental e simulada de pressão estática ao longo do equipamento para a condição E-3.

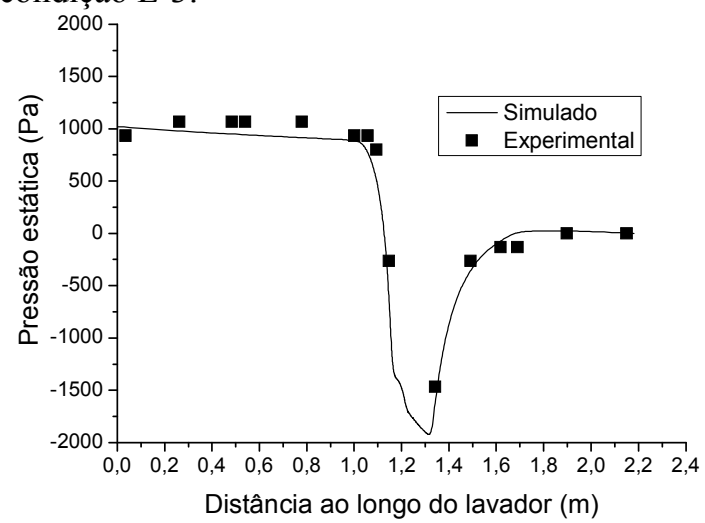

Figura 6 - Distribuição de tamanho de gotas experimental e por Rosin-Rammler condição E-1.

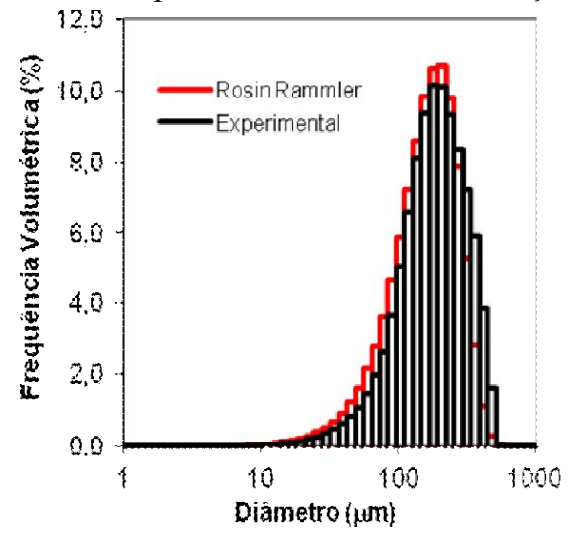

Tabela 2 - Parâmetros do modelo de distribuição de Rosin-Rammler

\begin{tabular}{|c|c|c|}
\hline Experimento & $\bar{D}(\mu \mathrm{m})$ & $\mathrm{n}$ \\
\hline E-1 & 190 & 2 \\
\hline E-2 & 230 & 2,2 \\
\hline E-3 & 183 & 2 \\
\hline E-4 & 162 & 1,7 \\
\hline E-5 & 160 & 1,9 \\
\hline
\end{tabular}

As Figuras 7 e 8 apresentam a distribuição de concentração da fase dispersa (líquido) simuladas, em $\mathrm{kg} / \mathrm{m}^{3}$, para as condições experimentais E-1 e E-5, respectivamente. Através dessas figuras podese verificar que ao adentrar a garganta do lavador a fase dispersa apresenta uma curvatura em virtude das forças de arraste do gás. Tal comportamento é condizente com os resultados experimentais obtidos por Guerra et al. (2012), Gonçalves et al. (2004) e Gonçalves (2000). Como pode ser visto na Figura 8, que mostra a injeção de líquido por dois orifícios, inicialmente os jatos seguem suas trajetórias individualmente, até um determinado ponto em que se encontram e acabam por ocasionar uma maior concentração de líquido no centro da garganta.

Figura 7 - Contornos de concentração $\left(\mathrm{kg} / \mathrm{m}^{3}\right)$ da fase dispersa condição E-1.
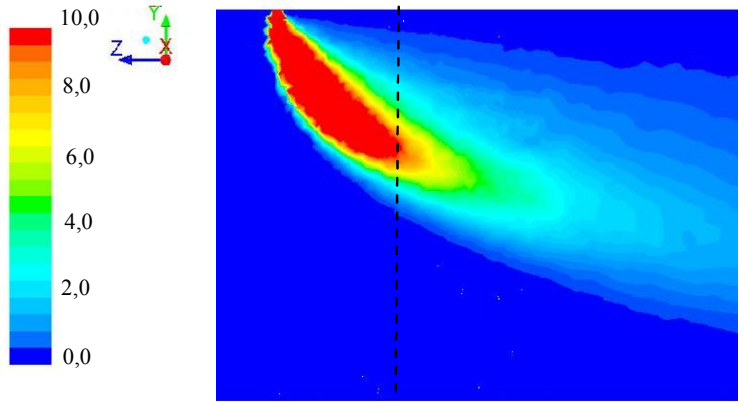

Figura 8 - Contornos de concentração $\left(\mathrm{kg} / \mathrm{m}^{3}\right)$ da fase dispersa condição E-5.

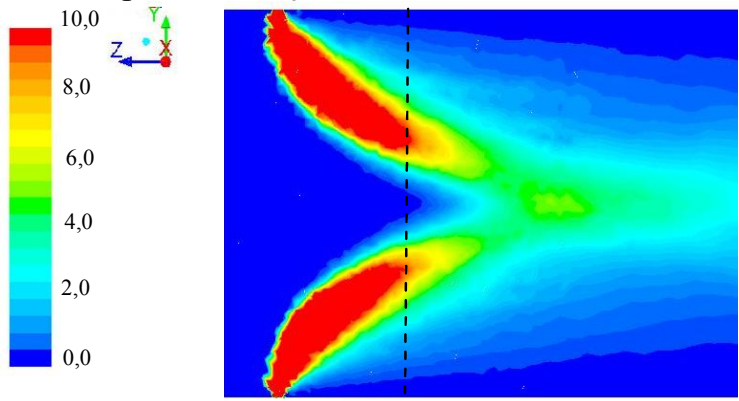

Nas Figuras 9 e 10 são apresentados os resultados simulados de fluxo normalizados pela concentração média em um plano localizado a $1,6 \mathrm{~cm}$ do ponto de injeção de líquido, posição onde os dados experimentais foram medidos experimentalmente. Tal plano de amostragem está localizado bem próximo ao ponto de injeção de líquido. No caso do experimento E-5 esse ponto está antes do 
encontro do líquido no ponto central da garganta. As indicações dos planos são apresentadas nas Figura 7 e 8 pela linha tracejada. Através das Figuras 9 e 10 é possível verificar que a dispersão do líquido experimental e simulada apresentaram comportamento simulares para ambos os casos. Para o experimento E-1 observa-se um único pico com alto fluxo de gotas na região central da garganta. No caso E-5 pode-se verificar dois picos acentuados com alto fluxo de líquido.

As porcentagens de líquido injetado que se depositaram nas paredes de equipamento como um filme (Ff) foram determinadas variando-se as vazões de líquido, como observado nos casos E-2, E-3 e E-4, isto é, vazões iguais a 300, 600 e $900 \mathrm{ml} / \mathrm{min}$, respectivamente, manteve-se a injeção de líquido por 2 orifícios e velocidade do gás na garganta igual a $59 \mathrm{~m} / \mathrm{s}$. Assim na Figura 11 pode-se observar as porcentagens de líquido que ficaram depositadas na garganta para as diferentes condições de vazão de líquido avaliadas.

Figura 9 - Perfil de dispersão de líquido para o caso E-1

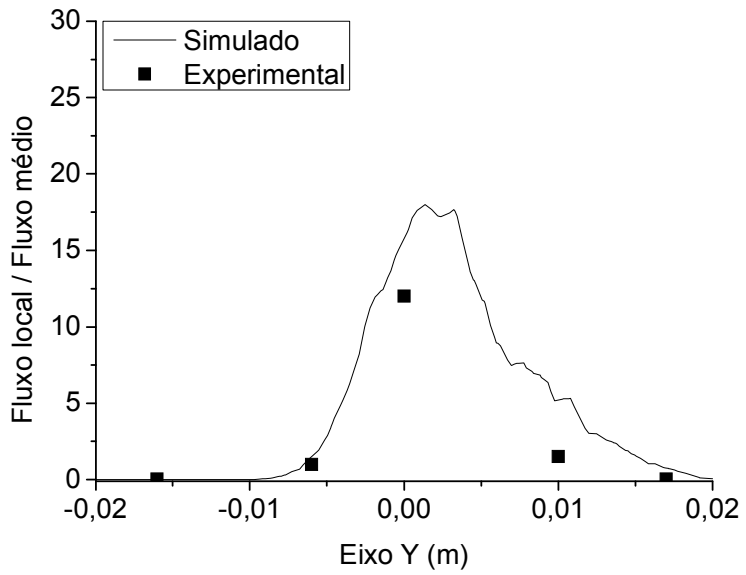

Figura 10 - Perfil de dispersão de líquido para o caso E-5.

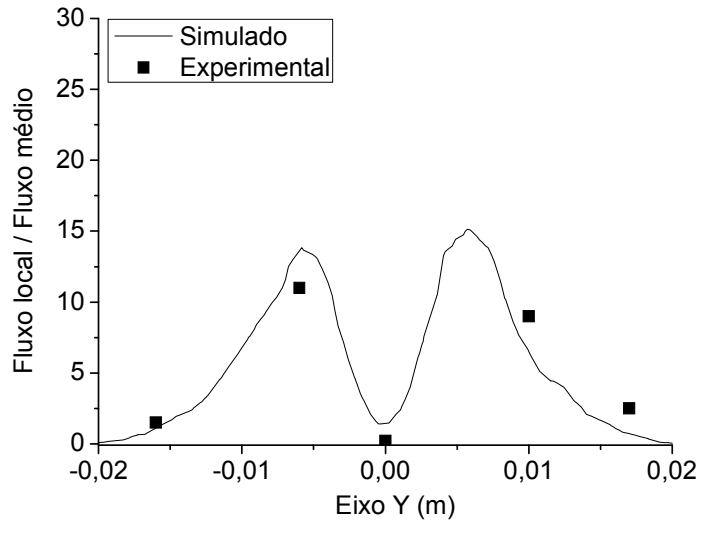

Figura 11 - Filme depositado na garganta do lavador em função da vazão de líquido.

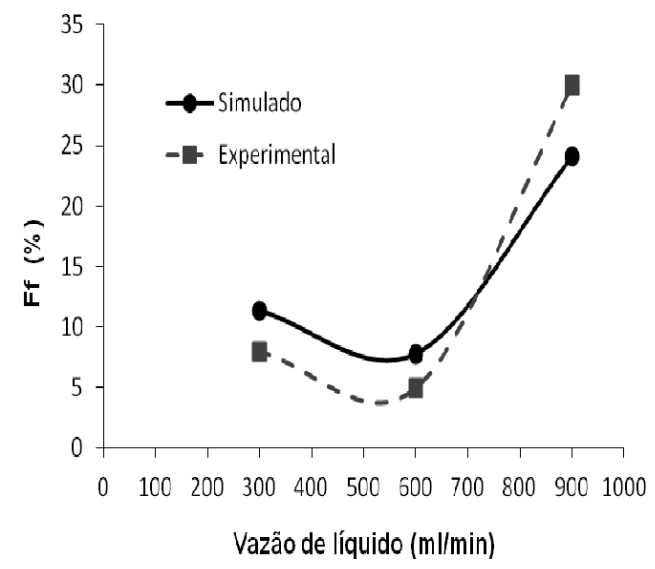

Como pode ser observado, os resultados experimentais e simulados apresentaram comportamento equivalentes. Pode-se verificar que para a vazão igual a $600 \mathrm{ml} / \mathrm{min}$ a porcentagem de filme aderida às paredes apresentou um ponto mínimo. Tal comportamento pode ser comprovado nas Figuras 12 a 14 que mostram os contornos de concentração na garganta do lavador para as diferentes condições de vazão de líquido avaliadas. Como pode ser visto nas figuras, para a condição de menor vazão de líquido, isto é $300 \mathrm{ml} / \mathrm{min}$, o líquido injetado fica muito próximo as paredes de injeção favorecendo a deposição nessas paredes. Já no caso observado na condição E-2 a vazão de 
$600 \mathrm{ml} / \mathrm{min}$ faz com que o líquido fique distribuído na região central da garganta, ocasionando menor deposição nas paredes da garganta. No caso E-3 a porcentagem de filme volta a aumentar devido a forte colisão entre jatos que ocasiona o espalhamento do líquido nas paredes opostas as de injeção.

Figura 12 - Contornos de concentração $\left(\mathrm{kg} / \mathrm{m}^{3}\right)$ da fase dispersa condição E-2.
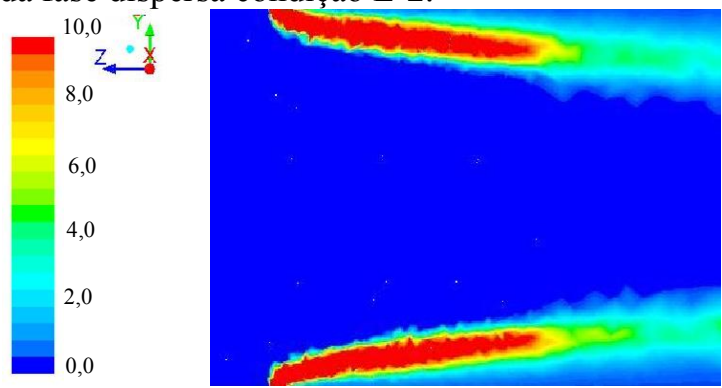

Figura 13 - Contornos de concentração $\left(\mathrm{kg} / \mathrm{m}^{3}\right)$ da fase dispersa condição E-3.
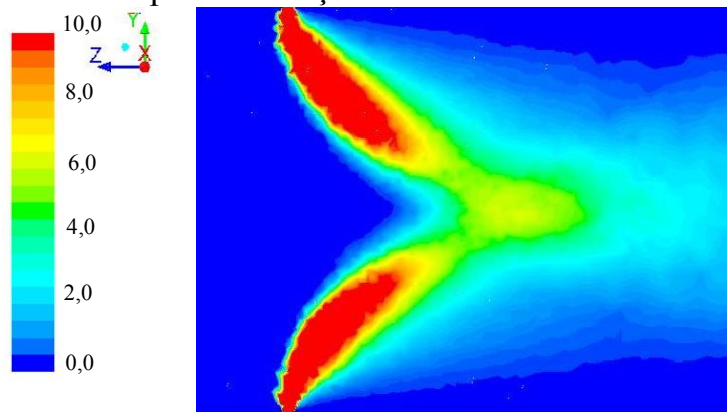

Figura 14 - Contornos de concentração $\left(\mathrm{kg} / \mathrm{m}^{3}\right)$ da fase dispersa condição E-4.

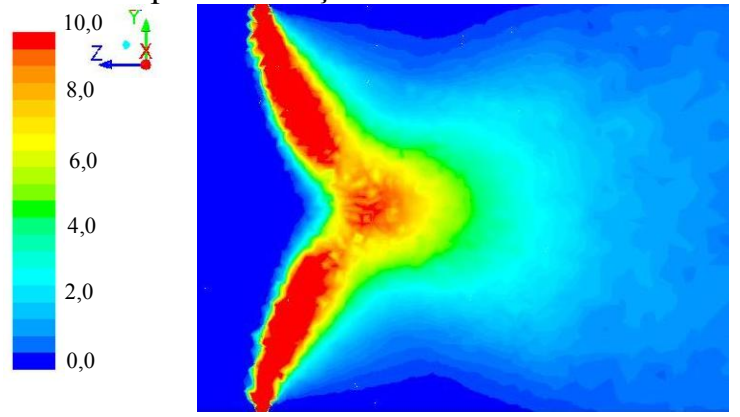

\section{CONCLUSÕES}

O modelo lagrangeano de fase discreta mostrou-se uma opção adequada para a simulação da distribuição de gotas no interior do lavador Venturi. O modelo apresentou boa previsão dos resultados experimentais de queda de pressão e dispersão de líquido no interior do equipamento para diferentes condições de vazão de líquido, orifícios de injeção de líquido e velocidade de gás. Além disso, o modelo apresentou um ponto de mínima formação de filme na garganta do equipamento para a condição de vazão de líquido em que a dispersão de gotas apresentava-se na região central da garganta, fenômeno também constatado experimentalmente.

\section{NOMENCLATURA}

Diâmetro médio do modelo de

$\bar{D} \quad$ distribuição de tamanho de $\quad \mu \mathrm{m}$

Rosin-Rammler

Porcentagem de filme líquido

Ff escoando nas paredes da garganta do lavador Venturi

Parâmetro de espalhamento do

n modelo de distribuição de tamanho de Rosin-Rammler

Q1 Vazão de líquido $\mathrm{ml} / \mathrm{min}$

$\mathrm{Vg}$ Velocidade de gás na garganta $\mathrm{m} / \mathrm{s}$ do lavador Venturi

\section{REFERÊNCIAS}

ANANTHANARAYANAN, N. V.; VISWANATHAN, S. Effect of nozzle arrangement on Venturi scrubber performance. Ind. Eng. Chem. Res. v. 38, p. 4889-4900, 1999.

EKMAN, F. O.; JOHNSTONE, H. F. Collection of aerosols in a Venturi scrubber. Ind. and Eng. Chem. v. 43, p. 1358-1363, 1951. 
FLUENT 14.0 Theory Guide. Fluent Inc.: Lebanon, NH, 2011.

GONÇALVES, J.A.S. Aspectos da modelagem matemática de lavadores Venturi. Tese de doutorado, Universidade Federal de São Carlos, São Carlos - Brasil, 2000.

GONÇALVES, J. A. S., COSTA, M. A. M.; AGUIAR, M. L.; COURY, J. R. Atomization of liquids in a Pease-Anthony Venturi scrubber - Part II. Droplet dispersion. J. Haz. Mat. p. 147-157, 2004.

GUERRA, V. G.; GONÇALVES, J. A. S.; COURY, J. R. Experimental investigation on the effect of liquid injection by multiple orifices in the formation of droplets in a Venturi scrubber. J. Haz. Mat., v.161, p.351359, 2009.

GUERRA, V. G . Investigação do efeito da injeção de líquido por orifícios múltiplos na formação de gotas em um lavador Venturi. 150p. Tese (Doutorado em Engenharia Química) -Universidade Federal de São Carlos, São Carlos, 2009.

GUERRA, V.G.; GONÇALVES, J.A.S.; COURY, J. R. Experimental verification of the effect of liquid deposition on droplet size measured in a rectangular Venturi scrubber. Chem. Eng. an Processing, v. 50, p. 11371142, 2011.

GUERRA, V.G. ; BETTEGA, R. ; GONCALVES, J. A. S. ; COURY, J. R. . Pressure Drop and liquid distribution in a Venturi Scrubber: Experimental data and CFD simulation. Ind. \& Eng. Chemistry Research, v. 51, p. 8049-8060, 2012.

HONDA, V.K.; BETTEGA, R.; GUERRA, V.G. Análise numérica CFD da dispersão de líquido em um lavador Venturi de seção retangular. Anais do $\mathbf{X X}$ Congresso Brasileiro de Engenharia Química, Florianópolis, 2014.
VISWANATHAN, S.; GNYP, A. W.; ST. PIERRE, C. C. Examination of gas flow in a Venturi scrubber. Ind. and Eng. Chem. Fund. v. 23, p. 303-308, 1984

\section{AGRADECIMENTOS}

Os autores agradecem ao $\mathrm{CNPq}$ pelo auxílio financeiro. 